\section{Dying within dying: Ethical dilemmas of treating terminally ill patients with acute life-threatening illnesses}

Sir,

With the advent of palliative care, severely ill patients with terminal illnesses are often treated in accordance with their autonomy and with dignity, compassion, and comfort. ${ }^{[1]}$ However, this most often happens if the patient is dying from the said terminal illness such as renal or heart failure or cancer. ${ }^{[2]}$ Such patients may choose to die at home or even in palliative care wards. It is a comforting feeling for physicians and families that nonbeneficial life-sustaining and often agonizing care is not being delivered against a patient's wishes. There are pathways, protocols, and advance care plans for identifying and allowing such patients to complete their journey at the end of life. ${ }^{[3]}$

However, an alarming number of patients with terminal illnesses fall through the cracks of this optimal situation. ${ }^{[4]}$ Patients may receive care that is not in keeping with their natural trajectory of illness or wishes if they are admitted with an acute potentially "reversible" pathology while having a background terminal illness such as developing pneumonia, suffering myocardial infarctions, or be involved in trauma. ${ }^{[5]}$ The rising costs of admitting and treating terminally ill patients with acute illness with modern day technology is unsustainable. The aim of this letter is to provide a brief review of the literature on the ethical difficulties that physicians and families face when decision-making in a terminally ill patient (at times with an advance care plan in place) is thrown off balance by a sudden acute illness. The question here is "should physicians feel morally obliged to treat an acute illness when the patient is already far along his or her end of life journey?"

The thematic analysis of these papers revealed the following subtopics: Family communication, reiteration of diagnosis, burden of critical treatment, and goal setting. There was general agreement that terminally ill patients should have continuity of care and preferably be referred to the same center familiar with their terminal diagnosis and end of life goals.

In an aging world with limited critical care resources, there are many demands on acute care settings such as Intensive Care Units. Patients who may not benefit from aggressive life-sustaining care perhaps should not be offered such treatment options such as life-saving surgery, if in fact it is merely prolonging their ultimate fate, unless it can add to alleviating suffering. Instead, effort and resources should be used in trying to match their goals and values, including palliation and providing mindful dignity and comfort. Often symptom control to provide relief is the driving force behind acute admissions in terminally ill patients; however, it seems that frank and consistent communication with patients and families may allay the ethical conflicts that usually arise when a patient presents in extremis while already dying from a separate illness including old age.

\section{Financial support and sponsorship}

Nil.

\section{Conflicts of interest}

There are no conflicts of interest.

Shahla Siddiqui ${ }^{1,2}$ 'Department of Anaesthesia and Intensive Care, Khoo Teck Puat Hospital, ${ }^{2}$ Department of Anaesthesia, Yong Loo Lin School of Medicine, National University of Singapore, Singapore

Correspondence: Dr. Shahla Siddiqui, Department of Anaesthesia and Intensive Care, Khoo Teck Puat Hospital, Singapore. E-mail: shahlasi@yahoo.com

\section{References}

1. Wallace CL. Family communication and decision making at the end of life: A literature review. Palliat Support Care 2015;13:815-25.

2. Hogden A, Greenfield D, Nugus P, Kiernan MC. Engaging in patient decision-making in multidisciplinary care for amyotrophic lateral sclerosis: The views of health professionals. Patient Prefer Adherence 2012;6:691-701.

3. Tsalatsanis A, Barnes LE, Hozo I, Djulbegovic B. Extensions to regret-based decision curve analysis: An application to hospice referral for terminal patients. BMC Med Inform Decis Mak 2011;11:77. 
4. Granda-Cameron C, Houldin A. Concept analysis of good death in terminally ill patients. Am J Hosp Palliat Care 2012;29:632-9.

5. Zhang Z, Chen ML, Gu XL, Liu MH, Cheng WW. Cultural and ethical considerations for cardiopulmonary resuscitation in Chinese patients with cancer at the end of life. Am J Hosp Palliat Care 2015;32:210-5.

This is an open access article distributed under the terms of the Creative Commons Attribution-NonCommercial-ShareAlike 3.0 License, which allows others to remix, tweak, and build upon the work non-commercially, as long as the author is credited and the new creations are licensed under the identical terms.

\begin{tabular}{|l|l|}
\hline \multicolumn{2}{|c|}{ Access this article online } \\
\hline Quick Response Code: & Website: \\
\hline & www.ijccm.org \\
\cline { 2 - 2 } & \\
\hline
\end{tabular}

How to cite this article: Siddiqui S. Dying within dying: Ethical dilemmas of treating terminally ill patients with acute life-threatening illnesses. Indian J Crit Care Med 2016;20:308-9 